\section{Complications of Gonorrhoea}

Apart from pelvic infections in women, complications of gonorrhoea have come to be regarded as uncommon to the point of rarity. Prompt treatment is usually sought by men and seems virtually to have eliminated both acute and chronic complications. Women have been less fortunate, however, owing to delay in treatment resulting from absence of symptoms or misinterpretation of the early trivial ill effects. Metastatic gonorrhoea is still described in the textbooks, but many experienced venereologists have never seen it. Nevertheless there have been occasional reports, chiefly from North America, of an apparently mild condition resulting from invasion of the blood stream by the gonococcus. Two such cases were reported in Britain by E. P. O'Sullivan' in 1964, and C. B. Wolff, H. V. Goodman, and J. Vahrman ${ }^{2}$ described four more cases in the B.M.f. earlier this year.

The condition is more common in women than men, and is characterized by mild systemic reaction with pyrexia, polyarthritis which tends to be migratory but may localize in a single joint, and lesions of the skin occurring in crops. These lesions, papular with a scanty peripheral distribution, are surrounded by erythema and tend to evolve into pustules. Some of the pustules are likely to be haemorrhagic, and the occurrence of haemorrhagic bullae has been described by H. Keil ${ }^{3}$ and by A. B. Ackerman. ${ }^{4}$ Large or small joints may be affected, and the skin overlying the joints may show erythema and even lymphangitis.

Wolff and his colleagues grew gonococci from the cervix uteri and from the blood stream in their first case, from joint fluid and the urethra in the second, from the blood in the third, and from the cervix and blood in the fourth. The condition responded well to penicillin. The fact that all four cases were diagnosed in one group of hospitals within a year (and in the same group in which two cases had been detected five years previously) suggests that these cases may be more common than is supposed and that lack of awareness may be a barrier to correct diagnosis. In differential diagnosis Reiter's disease has to be considered, and other possibilities are chronic meningococcal septicaemia and low-grade staphylococcal septicaemia. The increase in the spread of gonorrhoea is such that more of these cases are likely to occur.

Another complication which was always rare and is now practically forgotten is gonorrhoea perihepatitis. In the past it has been described only in women and usually as a sequel to pelvic infection. It may present with sudden onset of pain in the right hypochondrium, which may be referred to the right shoulder. The patient may be moderately or acutely ill with variable fever and signs suggesting peritonitis in the right upper quadrant of the abdomen. The symptoms and signs may suggest cholecystitis, pneumonia, or pleurisy. M. W. Kimball and $S$. Knee ${ }^{5}$ have recently described such a case in a man; the organism was recovered from the liver by biopsy. Presumably the condition remains rare, but it presents another possible diagnostic pitfall.

1 O’Sullivan, E. P., British Medical Fournal, 1964, 1, 1508.

2 Wolff, C. B., Goodman, H. V., and Vahrman, J., British Medical fournal, $1970,2,271$.

3 Keil, H., Quarterly fournal of Medicine, 1938, 7, 1.

- Ackerman, A. B., New England Fournal of Medicine, 1970, 282, 793.

5 Kimball, M. W., and Knee, S., New England fournal of Medicine, 1970, 282, 1082 .

\section{Laws for Fetuses}

Lawyers, like doctors, have their specialties, and what must be one of the newest branches of learning to be so marked out is the legal rights of the fetus. Does a fetus have a right to medical treatment, for instance? Does it have a right to recover damages for injury, and if so at what stage of its development?

These are the sort of questions being studied by Professor Sanford Katz, ${ }^{1}$ of the Boston College Law School, and they are likely to engage his attention as well as that of experts in many other countries for a long time yet. The beginning of human life is if anything more difficult to define than its end, and apart from the still unresolved debates centred on termination of pregnancy other questions are coming to the fore in relation to the use of fetuses and fetal material for research. A committee to study them, recently appointed by the Government, has as its chairman Sir John Peel and among its members two experienced lawyers. ${ }^{2}$ Again, the unborn fetus may be given medical treatment-for example, a blood transfusion in cases of rhesus incompatibility. But the law on at least some of the relationships between doctor and fetus is far from clear. $^{3}$ It is to be hoped that others of his profession will join Professor Katz in elucidating it, and doctors too should make their views heard.

\section{Wrong Operations}

The tragedy of operating on the wrong patient or the wrong limb is matched by the simplicity of the measures that will effectually prevent it. Yet according to the secretary of the Medical Defence Union, from whom a letter appears at page 461 this week, these avoidable mishaps continue to be reported. He states that last year the M.D.U. dealt with 25 such cases and in the first seven months of this year no fewer than another 17. Unfortunately cases of this kind show no signs of diminishing in frequency, for in the six years from 1963 to 1968 the M.D.U. received reports of 126, an average of 21 a year.

Routine procedures for the unmistakable identification of patients from beginning to end of their stay in hospital and for the indelible marking of the part to be operated on before the patient reaches the theatre should be in force at every hospital. The defence societies have given and will give advice on this when asked. Clearly rules in themselves even when followed to the letter are not enough, for to err is human, and human error has a way of taking us all unawares. It is the heavy burden of doctors, as of generals, that their mistakes can have tragic consequences. But are proper safeguards a part of the daily routine in every hospital? The letter from the M.D.U. suggests that they are not.

\footnotetext{
Key Issues in Infant Mortality, ed. F. Falkner. Bethesda, Maryland, U.S.A., National Institute of Child Health and Human Development,

British Medical fournal, 1970, 3, 292.
}

3 British Medical fournal, 1970, 2, 433. 